to be published in Int. J. of PIXE

\title{
ELEMENTAL ANALYSIS OF URANOUCHI BAY SEABED SLUDGE USING PIXE
}

\author{
M HASNAT KABIR and TADASHI NARUSAWA \\ Department of Electronic and Photonic Systems Engineering \\ Kochi University of Technology, Taso-Yamada, Kochi 782-8502, JAPAN \\ 088401u@gs.kochi-tech.ac.jp \\ FUMITAKA NISHIYAMA \\ Department of Power Engineering and Applied physics \\ Hiroshima University, 1-4-1 Kagamiyama, Higashi-Hiroshima, Hiroshima, 739-8525, JAPAN \\ fnishi@hiroshima-u.ac.jp \\ KATSUHIRO SUMI \\ Department of Environmental Systems and Engineering \\ Kochi University of Technology, Taso-Yamada, Kochi 782-8502, JAPAN \\ sumi.katsuhiro@kichi-tech.ac.jp
}

\begin{abstract}
Elemental analysis was studied of Uranouchi bay (Kochi, Japan) seabed sludge using a pioneer technique for elemental analysis named Particle Induced X-ray Emission (PIXE). Seabed sludge contamination with heavy metal ions as well as toxic elements is one of the most serious environmental problems. Nowadays it becomes a major issue for human. The aim of this study is to investigate the polluted area of the bay by heavy and toxic elements. Analyzing eleven different places sample of this bay, seventeen elements were detected with some toxic elements such as $\mathrm{Cr}, \mathrm{Ni}$, $\mathrm{Cu}$ and $\mathrm{Zn}$. Results suggest that the center region of the bay is more polluted by the high concentration of heavy as well as toxic elements.
\end{abstract}

Keywords: Uranouchi bay; Seabed Sludge; PIXE

\section{Introduction}

Uranouchi bay of Kochi prefecture, Japan is well-known for natural beauty and fishfarming. The water and seabed of this bay are not clean now. The increasing elemental concentrations of heavy elements are the reason for dirtiness of the bay. Fishermen grow fish in this bay and put fish food profoundly. The concentration of different elements in fish food is extremely enriched. Some parts of this food are taken by fish and rest of foods is accumulated into seabed sludge. On the other hand, a large number of small boats move inside the bay. Boat fuel is also another reason for creating grimy sludge. Therefore, the global ecological system of the bay has been changed gradually. The analysis of seabed sludge is important on the aspect of understanding about elemental concentration those are dissolved in the sludge and harmful for environment. Several analytical techniques have been used for this purpose, but the preparation of sample is complicated and takes a long time. The ion beam technique, especially Particle Induced $\mathrm{X}$-Ray Emission (PIXE) [1] is a powerful technique for material analysis. However, the sample preparation technique is easy and takes only a short time. This technique is also very popular for relatively high sensitivity, multi-elemental and non-destructive nature. Our aim of the study is to find out hazardous area of the bay with high concentration of toxic as well as heavy elements. 


\section{Sampling}

The Uranouchi bay is about $12 \mathrm{~km}$ long and leads to the open Pacific Ocean through a shallow mouth ( $\sim 300 \mathrm{~m}$ wide). Samples were collected from eleven different places of this bay as shown in Fig.1.

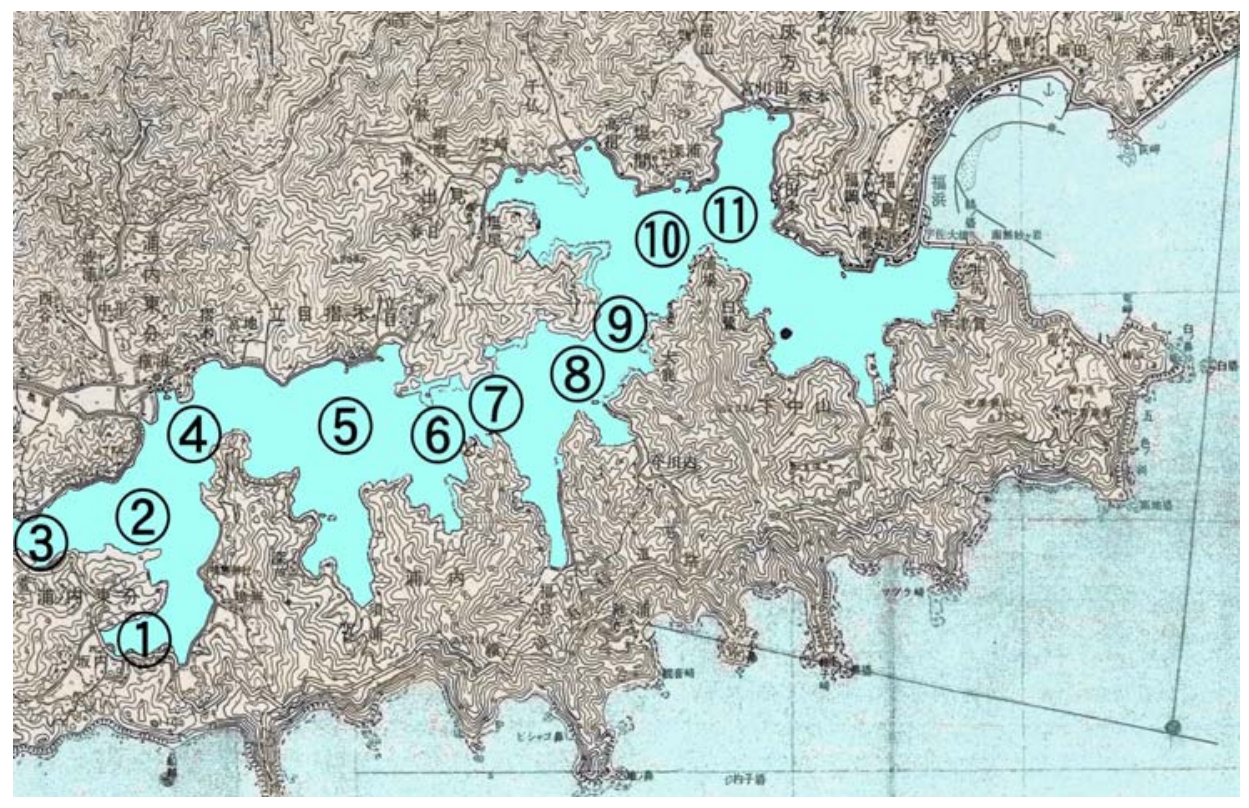

Fig.1: Eleven sampling points of seabed sludge from Uranouchi Bay.

Samples were collected randomly; Ekman dredge sampler was used to collect seabed sludge from the top of the bottom sediment. Ekman dredges are preferred in soft mud, silt, or fine sand [2]. Then, samples were passed through a $2 \mathrm{~mm}$ metal sieve for removing stone, wood and algae type goods. After that samples were preserved in a refrigerator in glass bottles with small amount of Ar gas.

\section{Sample preparation:}

Wet sludge samples were dried at room temperature. For proper ingredient mixing of all elements, samples were made into powder form. Carefully weighted $10 \mathrm{mg}$ dried sludge sample was mixed with $1 \mathrm{ml}$ polyvinyl acetate (1000 ppm PVAc) and $0.5 \mathrm{ml}$ Hiviswako (0.5\%). After proper mixing, $15 \mu$ liquid sample was taken for analysis which contained $100 \mu \mathrm{g}$ sludge. Droplet of the acquired solution was then spotted on to a $4 \mu \mathrm{m}$ thick polypropylene film which was used as substrate for samples to form a circular target spot with a size of around $4 \mathrm{~mm}$ in diameter. At room temperature, samples were placed inside of desiccators until they were dried. The sample was then ready for PIXE measurement. From one sample solution, three targets were made and each target was measured separately. 


\section{Experimental}

The proton beam from the 2.5 MV Van de Graaff accelerator at Hiroshima University was used for this study. The samples were irradiated in a vacuum chamber with $6 \mathrm{~mm}$ in diameter ion beam which covered the entire area of target. Characteristic x-rays from targets were measured with a $\mathrm{Si}(\mathrm{Li}) \mathrm{SL80175}$ Canberra detector $(25.4 \mu \mathrm{m}$ thick Be window). Detector was connected to a multi-channel analyzer for converting analog data to digital. Detector sensitivity area, resolution and Si thickness were $80 \mathrm{~mm}^{2}, 167 \mathrm{eV}$ fwhm at $5.9 \mathrm{keV}$ and $5 \mathrm{~mm}$, respectively. Detector angle from the beam line was $150^{\circ}$. Two spectra were obtained for each target: the first one was for detection of $\mathrm{Z} \geq 20$ elements with $2.5 \mathrm{MeV}$ proton energy, $5 \mathrm{nA}$ beam intensity and $2 \mu \mathrm{C}$ accumulated charge; the second one was for $\mathrm{Z}<20$ elements with $1.25 \mathrm{MeV}$ proton energy, $1.5 \mathrm{nA}$ beam intensity and $1 \mu \mathrm{C}$ accumulated charge. $250 \mu \mathrm{m}$ thick mylar filter without any hole and a $2.4 \mathrm{~mm}$ hole (funny) were placed in front of detector for the first and the second case, respectively. Fig.2 and Fig.3 are respectively the typical PIXE spectra for $2.5 \mathrm{MeV}$ and $1.25 \mathrm{MeV}$ proton of Sam1(Sample number 1). It can be seen from Fig.2 that the $\mathrm{Z} \geq$ 20 element peaks appear strongly. On the other hand, in Fig.3, the $Z<20$ element peaks are shown prominently and the higher $\mathrm{Z}$ element peaks are not shown because the ionization cross-section is lower for heavy elements in low energy.
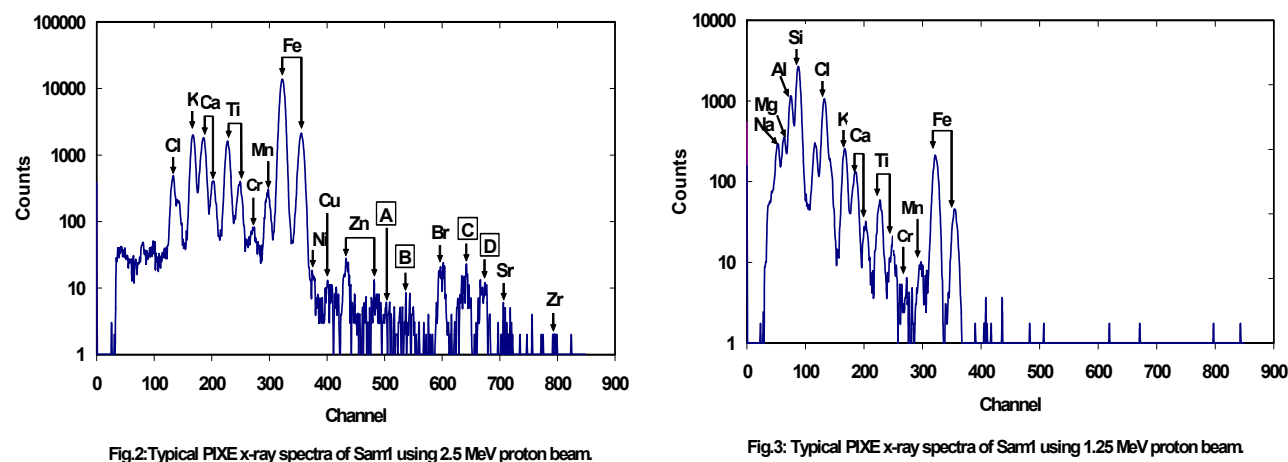

Fig.4 and Fig.5 are the spectra for $4 \mathrm{MeV} \mathrm{He}{ }^{++}$and $2.5 \mathrm{MeV} \mathrm{H}^{+}$of sample Sam7, respectively. These two spectra were measured in different conditions. So, we can not compare directly, however, we see at a glance that for lower $\mathrm{Z}$ elements $4 \mathrm{MeV} \mathrm{He}^{++}$ analysis has almost equivalent relative sensitivity compared with the proton case. Ionization cross-section is proportional to the projectile energy and will be maximized when the projectile energy is harmonized with the orbital velocity of ejected electrons. Proton ions have higher energy in contrast to helium ions. Therefore, in the proton case, the ionization cross-section is generally higher as compared with the helium case. However, the figure shows that, in limited cases helium ions have sufficiently high sensitivity. 

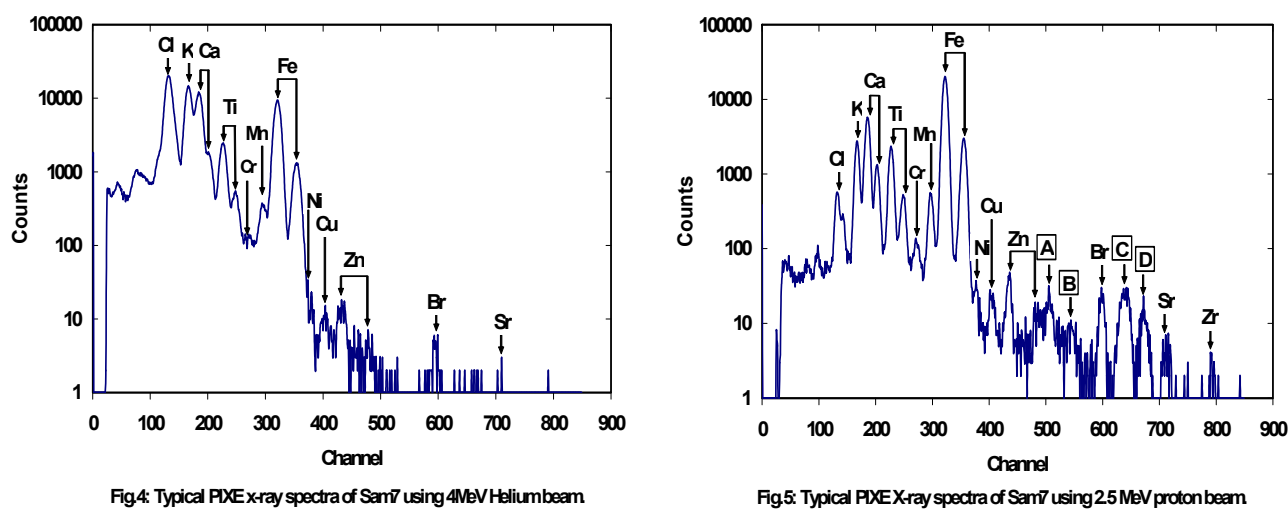

Fig5: Typical PIXEX-ray spectra of Sam7 using 25 MeV proton beam

\section{Results and Discussion}

Seventeen elements were detected in the analysis of eleven sample areas of Uranouchi bay. Typical PIXE spectra of sample number Sam7 for $2.5 \mathrm{MeV}$ proton energy is shown in Fig.5. Detected elements are designated in this figure. Though, $\mathrm{Zr}$ is detected at some sample area as low amount, but in this paper we do not consider $\mathrm{Zr}$ concentration. However, 4 extra peaks are clearly shown in Fig. 5 as indicated by A, B, C and D at channel 504, 540, 640 and 672, respectively. Peak (A), (B), (C) and (D) are the sum peak of $\mathrm{Ca}\left(\mathrm{K}_{\alpha}\right)+\mathrm{Fe}\left(\mathrm{K}_{\alpha}\right), \mathrm{Ca}\left(\mathrm{K}_{\alpha}\right)+\mathrm{Fe}\left(\mathrm{K}_{\beta}\right), 2 * \mathrm{Fe}\left(\mathrm{K}_{\alpha}\right)$ and $\mathrm{Fe}\left(\mathrm{K}_{\alpha}\right)+\mathrm{Fe}\left(\mathrm{K}_{\beta}\right)$, respectively. Experimental system has pile-up rejection. Therefore, these peaks come when the system is unable to discriminate exactly simultaneous protons. If we compare Fig.5 (Sam7) and Fig.6 (Sam11), it is clearly shown that the elemental concentration of Sam7 is much higher than Sam11.

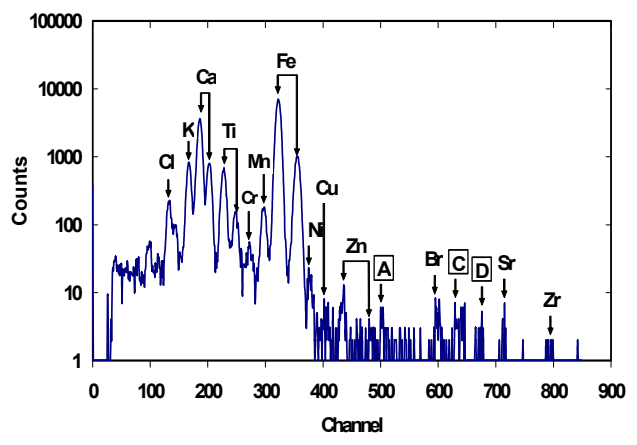

Fig6: Typical PIXE x-ray spectra of Sam11 using 2.5 MeV proton beam

Atomic Absorption Spectrometry (AAS) standard sample were used as calibration standards for the calculation of elemental concentration. The sensitivity of each element $i$ is calculated using the following equation:

$$
S_{i}=\frac{Y_{i}}{Q_{i}}
$$


where $S_{i}=$ sensitivity for element $i, Y_{i}=$ peak height (counts per $\mu \mathrm{g}$ ) for standard sample and $Q_{i}=$ the value of charge $(\mu \mathrm{C})$ accumulated during standard sample measurement. For calibration, sensitivity versus atomic number curves are shown in Fig.7(a) and Fig.7(b).
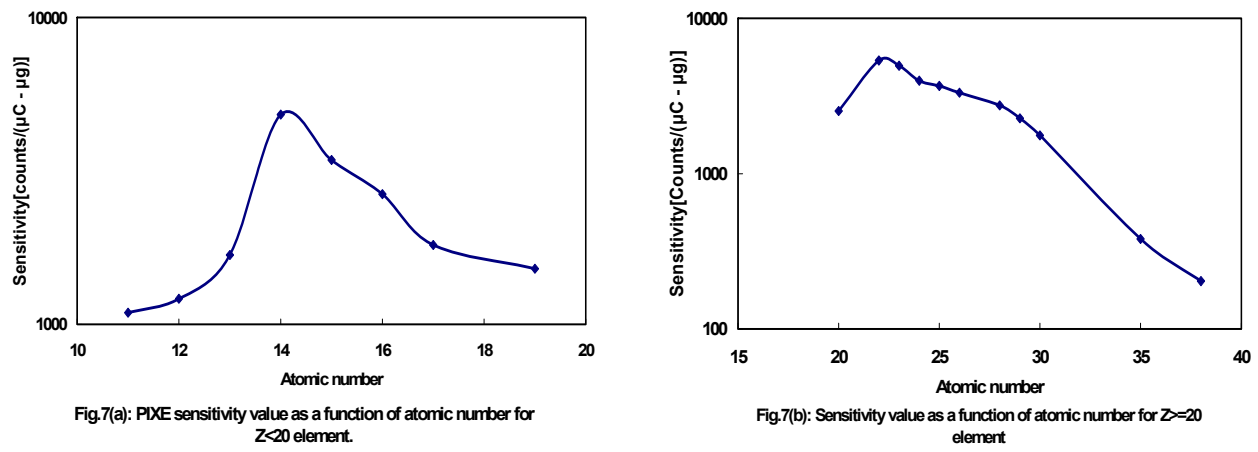

The concentration of each target element is calculated using the following equation:

$$
C_{i t}=\frac{Y_{i t} / Q_{i t}}{S_{i t}}
$$

where $C_{i t}=$ concentration of $i$ target element, $Y_{i t}=$ average peak height of target element, $Q_{i t}=$ value of accumulated charge $(\mu \mathrm{C})$ during the measurement of target and $S_{i t}=$ sensitivity factor for $i$ element.

Every sample was irradiated three times and then the elemental concentration of one sample was calculated from data after averaging peak height over measurements of three targets. It is noted that about 66 spectra from 11 samples are considered for calculation. The elemental peak concentrations of different elements are shown in Table 1. Na, Mg, $\mathrm{Al}, \mathrm{Si}, \mathrm{S}, \mathrm{Cl}, \mathrm{K}, \mathrm{Ca}$ and $\mathrm{Fe}$ are detected as major elements whereas Ti, Cr, Mn, Ni, Cu, Zn, $\mathrm{Br}$ and $\mathrm{Sr}$ are detected as trace elements. Some toxic elements [3-5] such as $\mathrm{Cr}, \mathrm{Ni}, \mathrm{Cu}$ and $\mathrm{Zn}$ are significantly increased in some sampling area with respect to other areas. 
to be published in Int. J. of PIXE

Table 1. Elemental concentration at different regions of Uranouchi bay. Results are shown in units of $100 \mu \mathrm{g} / \mathrm{g}$.

\begin{tabular}{lrrrrrrrrrrr}
\hline Elements & Sam1 & Sam 2 & Sam 3 & Sam 4 & Sam 5 & Sam 6 & Sam 7 & Sam 8 & Sam 9 & Sam 10 & Sam 11 \\
\hline $\mathrm{Na}$ & 112.76 & 121.61 & 119.54 & 164.84 & 171.92 & 146.09 & 151.40 & 116.73 & 143.83 & 108.30 & 65.23 \\
\hline $\mathrm{Mg}$ & 132.10 & 128.69 & 132.01 & 137.43 & 187.27 & 173.02 & 188.45 & 138.34 & 161.30 & 133.20 & 75.47 \\
\hline $\mathrm{Al}$ & 421.83 & 385.77 & 455.21 & 352.59 & 456.06 & 309.68 & 569.06 & 339.96 & 409.90 & 332.92 & 179.00 \\
\hline $\mathrm{Si}$ & 415.18 & 394.78 & 460.37 & 356.85 & 509.78 & 332.73 & 628.69 & 391.39 & 504.10 & 433.71 & 262.79 \\
\hline $\mathrm{S}$ & 48.04 & 59.28 & 56.33 & 57.40 & 61.80 & 37.74 & 67.27 & 43.70 & 45.79 & 34.01 & 13.12 \\
\hline $\mathrm{Cl}$ & 318.24 & 346.96 & 340.07 & 477.45 & 527.42 & 284.55 & 421.65 & 355.61 & 413.39 & 291.26 & 135.24 \\
\hline $\mathrm{K}$ & 70.20 & 65.79 & 73.89 & 67.59 & 82.07 & 53.26 & 95.28 & 63.31 & 74.41 & 60.26 & 33.68 \\
\hline $\mathrm{Ca}$ & 46.78 & 48.03 & 43.67 & 45.72 & 98.35 & 55.37 & 149.12 & 109.02 & 165.05 & 175.55 & 98.22 \\
\hline $\mathrm{Ti}$ & 14.44 & 14.35 & 16.36 & 13.59 & 17.69 & 18.48 & 22.28 & 15.79 & 20.24 & 18.09 & 8.63 \\
\hline $\mathrm{Cr}$ & 1.04 & 1.00 & 1.15 & 1.00 & 1.47 & 1.39 & 1.81 & 1.24 & 1.60 & 1.57 & 1.45 \\
\hline $\mathrm{Mn}$ & 2.93 & 3.45 & 3.69 & 3.16 & 5.73 & 5.37 & 7.76 & 5.58 & 6.91 & 6.00 & 3.65 \\
\hline $\mathrm{Fe}$ & 205.87 & 206.06 & 225.63 & 178.82 & 256.16 & 263.11 & 315.51 & 233.02 & 306.60 & 256.17 & 135.57 \\
\hline $\mathrm{Ni}$ & 0.32 & 0.36 & 0.41 & 0.32 & 0.45 & 0.44 & 0.61 & 0.53 & 0.69 & 0.60 & 0.39 \\
\hline $\mathrm{Cu}$ & 0.34 & 0.31 & 0.28 & 0.29 & 0.48 & 0.50 & 0.58 & 0.42 & 0.56 & 0.46 & 0.21 \\
\hline $\mathrm{Zn}$ & 0.82 & 0.77 & 0.87 & 0.65 & 1.10 & 1.10 & 1.20 & 1.03 & 1.10 & 0.77 & 0.45 \\
\hline $\mathrm{Br}$ & 2.85 & 2.46 & 3.20 & 3.86 & 3.90 & 3.64 & 3.68 & 3.51 & 3.64 & 2.11 & 0.96 \\
\hline $\mathrm{Sr}$ & 1.48 & 1.48 & 0.90 & 0.99 & 1.23 & 1.40 & 2.05 & 1.15 & 1.89 & 2.05 & 0.90 \\
\hline
\end{tabular}

The concentration of all major elements is higher in different sampling area, especially sample area Sam7, as compared to Sam11. In Sam7, S concentration is dramatically increased by five times than Sam11. On the other hand, the concentration level of S is almost similar in Sam2, Sam3, Sam4 and Sam5. Ca concentration is increased from inlet of the bay until sample area Sam7. However, it is decreased in the inside of the bay and it is similar in Sam1, Sam2, Sam3 and Sam4. Though, we do not know the actual reasons for decreasing the concentration of Ca in these regions, it is not suitable for fish cultivation. On the other hand, the trace element $\mathrm{Cr}$ concentration is lower in Sam2 and Sam3 but it is much higher in Sam7. Ni concentration is higher in Sam9 but lower in Sam1 and Sam4. The concentration of $\mathrm{Cu}, \mathrm{Zn}$ and $\mathrm{Sr}$ is much higher in Sam7 in contrast to Sam11. Br concentration is higher in Sam5.

In summary, we see that elemental concentration is increased in the center region of the Uranouchi bay. The concentration of different elements is much lower near the bay inlet side than other regions of the bay. Perhaps water circulation is high near the bay inlet and probably people do not use this area much more for other purposes especially for the cultivation of fish. The most prominent reason for increasing elemental concentration in Uranouchi bay is fish farming. Fisherman puts a huge amount of fish food in the bay. A part is taken by fish but rest of them falls on seabed and increases the concentration of elements in the sludge. Fuel of sea boat is another significant reason because a large number of sea boats are used in this bay. Probably some other reasons have influenced to increase the elemental concentration but we are not sure now. 
Fig.8 shows the concentration ratio of toxic elements. All values are divided by their lowest value for comparison of the ratios. It can be seen from this figure that the concentration of $\mathrm{Cr}, \mathrm{Ni}, \mathrm{Cu}$ and $\mathrm{Zn}$ is pronouncedly increased in Sam5, Sam6, Sam7 and Sam9 in contrast to other samples. Cr, Zn and $\mathrm{Cu}$ are more than 2.48, 2.6 and 2.72 times higher respectively in Sam7; whereas Ni is 2.58 times higher in Sam9 in contrast to their lower values. Trace heavy metals as well as toxic elements have been changed the ecological system of this bay and causing deleterious effects on fish and other aquatic organism.

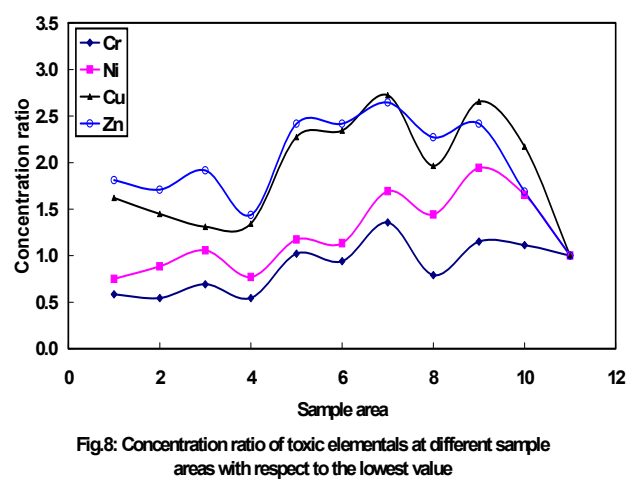

Though there is no general agreement concerning the maximum concentrations limit of various elements in seabed sludge. So, if we consider the concentrations of different elements of Sam11 as a reference value then all other sampling areas are polluted especially Sam5, Sam6, Sam7 and Sam9 in contrast to Sam11. Sam7 is most polluted among them.

\section{Conclusion}

Seventeen elements are detected with some toxic elements such as $\mathrm{Cr}, \mathrm{Ni}, \mathrm{Cu}$ and $\mathrm{Zn}$ from seabed sludge of the Uranouchi bay. The center region of this bay is more polluted in contrast to other parts. The highest contamination is found for $\mathrm{Cu}$ and $\mathrm{Zn}$ in Sam7 which is more than 2.72 and 2.6 times, respectively higher as compared to Sam11.

\section{References}

1. Johansson S. A. E. and Campbell J. L., PIXE: A novel technique for elemental analysis (John Wiley \& Sons, Chichester, 1988).

2. http://www.umanitoba.ca/faculties/science/zoology/faculty/hann/z350/\#Ekman

3. J. Pearson, F. Lu and K. Gandhi, Disposal of wool scouring sludge by composting, AUTEX Research Journal, Vol. 4, No3, (September 2004), 147-156

4. R. M. Bradley, G.R. Dhanagunan, Sewage sludge management in Malaysia, Int. J. Water, Vol. 2, No. 4, (2004), 267-283

5. V. Vijayan, R. K. Choudhury, B. Mallick, S. Sahu, S. K. Choudhury, H. P. Lenka, T. R. Rautray and P. K. Nayak, External particle-induced x-ray emission, Current science, Vol.

85, NO. 6, (25 September 2003), 772-777 